\title{
Valuing Catastrophe Bonds Involving Credit Risks
}

\author{
Jian Liu, ${ }^{1}$ Jihong Xiao, ${ }^{1}$ Lizhao Yan, ${ }^{2}$ and Fenghua Wen ${ }^{3}$ \\ ${ }^{1}$ School of Economics and Management, Changsha University of Science and Technology, Changsha 410004, China \\ ${ }^{2}$ Press, Hunan Normal University, Changsha 410081, China \\ ${ }^{3}$ Business School, Central South University, Changsha 410083, China
}

Correspondence should be addressed to Fenghua Wen; wfh@amss.ac.cn

Received 12 January 2014; Accepted 1 April 2014; Published 17 April 2014

Academic Editor: Wei Chen

Copyright (C) 2014 Jian Liu et al. This is an open access article distributed under the Creative Commons Attribution License, which permits unrestricted use, distribution, and reproduction in any medium, provided the original work is properly cited.

\begin{abstract}
Catastrophe bonds are the most important products in catastrophe risk securitization market. For the operating mechanism, CAT bonds may have a credit risk, so in this paper we consider the influence of the credit risk on CAT bonds pricing that is different from the other literature. We employ the Jarrow and Turnbull method to model the credit risks and get access to the general pricing formula using the Extreme Value Theory. Furthermore, we present an empirical pricing study of the Property Claim Services data, where the parameters in the loss function distribution are estimated by the MLE method and the default probabilities are deduced by the US financial market data. Then we get the catastrophe bonds value by the Monte Carlo method.
\end{abstract}

\section{Introduction}

The securitization of catastrophe risk springing up in the early 1990s has created a direct link between the insurance industry and capital market. There are a variety of catastrophe risk securitization instruments, such as options, swaps, and bonds. Catastrophe bonds (CAT bonds), the largest issued and most successful instrument among them, have topped \$6 billion in 2013 and are set to be the highest since 2007, according to Artemis, a deal tracker [1]. CAT bonds are usually insurance-linked and meant to raise money in case of a catastrophic event such as a hurricane or earthquake, so that insurance companies can hedge their exposure by transferring catastrophe risk to a wide pool of willing investors. Compared with other fixed income asset classes, CAT bonds offer high yield as the total returns were almost 9.5\% in 2013, according to a Swiss Re index [1]. Furthermore, CAT bonds are not closely linked with the stock market or economic conditions, so they offer significant attractions to investors.

The development of CAT bonds market depends on the reasonable prices, so the scientific pricing is the key problem to the field of CAT bonds research. As a kind of catastrophe risk securitization product,, the value of CAT bonds results from the probability of the catastrophe risk and the loss in the catastrophe, for CAT bonds have the dual properties of bonds and options. Moreover, for the highly skewed property of the catastrophe risk distribution, valuing CAT bonds has become very complicated.

The main pricing models of CAT bonds, including Kreps model [2], LFC model [3, 4], Christofides model [5], and Wang two-factor model [6], are all using the quantitative methods to estimate essential factors of the price and then price the CAT bonds with them. Zimbidis et al. [7] use Extreme Value Theory to get the numerical results of CAT bonds prices under stochastic interest rates in an incomplete market framework. Z.-G. Ma and C.-Q. Ma [8] derive a bond pricing formula under stochastic interest rates with the losses following a compound nonhomogeneous Poisson process and find the numerical solution for the price of catastrophe risk bonds. Li et al. [9] study a representative agent-pricing model of the multievent CAT bonds by the data of catastrophic insured property losses of typhoon in China. Based on the idea of layered pricing, Xiao and Meng [10] use the extreme value model to discuss the pricing of the excess-of-loss reinsurance premium with different attachment points. Nowak and Romaniuk [11] use Monte Carlo simulation method to price the CAT bonds with different payoff functions. However, most of the literature in CAT bonds pricing research does not take the credit risk influence into account. Actually, the credit risk has the 
probability of existence for the operating mechanism of CAT bonds. So it is necessary to fully consider the credit risk in valuing research, which can improve the pricing validity.

This paper presents a pricing model of CAT bonds with credit risks and conducts an empirical analysis of the US catastrophe market data using the Extreme Value Theory, where the parameters in the loss function distribution are estimated by the MLE method and the default probabilities are deduced by the US financial market data. Furthermore, based on the theoretical pricing formula, we get the CAT bonds value by the Monte Carlo method.

\section{Operating Mechanism of CAT Bonds}

There are four main participants in CAT bonds: sponsor, special purpose vehicle (SPV), investor, and trustee. The sponsor usually is an insurance company or a reinsurance company which signs a reinsurance contract with SPV and pays the reinsurance premium to SPV. SPV connects the insurance market and the capital market and converts the reinsurance premium into CAT bonds which are issued to investors. Then the reinsurance premium and the funds coming from CAT bonds investors are deposited in the trust account of the trustee and they are invested in short-term securities with low risk. When a catastrophic event takes place and its loss is higher than the prespecified trigger, SPV will provide compensation, which is from the loss of CAT bonds investors, to the sponsor according to the contract. In this case, investors only receive a part of the principal and interest. If the catastrophic risk event does not occur or trigger during the term of the CAT bond, bonds investors will receive their principal plus a high-yield compensation for the catastrophic risk exposure $[12,13]$.

It follows that SPV is the key to the CAT bonds issue and its operation is directly related to the expected effect of CAT bonds. SPV is the intermediary in the securitization of catastrophe risk and has a significant role in the risk diversification and financing funds. SPV converts the constant return of the high security assets into float return using swaps and forwards via the trustees, who manage the funds, in order to pay interests to CAT bonds investors. However, the final appreciation of the capital depends on the credit rating of the counterparty. If the credit rating of the counterparty is low, the funds may shrink. In this case, investors of CAT bonds will not receive the high-yield predetermined compensation. It means that the CAT bonds have the credit risk, so in this paper we consider the influence of the credit risk to CAT bonds pricing.

\section{Valuation Framework}

3.1. Pricing Expression of CAT Bonds. Suppose the financial market is frictionless and arbitrage-free. The uncertainty in the market is characterized by the probability space $\left(\Omega, \mathscr{F},\left\{\mathscr{F}_{t}\right\}_{t \geq 0}, P\right)$, where $\Omega$ is the state space, $\mathscr{F}$ is the $\sigma$ algebra of measurable events, and $P$ is the market probability measure. The maturity date of a CAT bond is $T$ that is divided into $n$ period with continuous trading interval $\Delta t$.
An increasing filtration $\mathscr{F}_{t} \subset \mathscr{F}, t \in[0, T]$. The investor receives the predetermined interest at the end of each period and the interest of the current period and the whole principal in time $T$. The amount of the interest or the principal depends on whether the loss of the catastrophic event exceeds the trigger level. In this paper, when considering the credit risk of the CAT bond, the investment income also depends on the probability of default at each period. Suppose the probability of default at period $i$ is $\lambda_{i}$ and the recovery rate is a constant $\theta$. Let $H_{i}$ denote the payment amount of the CAT bond at period $i$ which can be expressed as follows.

When $1 \leq i \leq n-1$,

$$
H_{i}= \begin{cases}C_{i}, & I_{i} \leq M, \text { if not default } \\ \theta C_{i}, & I_{i} \leq M, \text { if default } \\ k C_{i}, & I_{i}>M\end{cases}
$$

When $i=n$,

$$
H_{n}= \begin{cases}C_{n}+F, & I_{n} \leq M, \text { if not default, } \\ \theta\left(C_{n}+F\right), & I_{n} \leq M, \text { if default, } \\ k\left(C_{n}+F\right), & I_{n}>M,\end{cases}
$$

where $F$ is the principal of the CAT bond, $C_{i}$ is the interest of period $i, k$ is the obtained ratio of interest and the principal when the CAT bond triggers, $I_{i}$ is the loss amount of the catastrophic event at period $i$, and $M$ is the amount of the loss trigger.

Then, the price of the CAT bond at time 0 is

$$
V=E\left[\sum_{i=1}^{n} e^{-r \cdot i \Delta t} H\left(\lambda_{i}, I_{i}\right)\right],
$$

where

$$
H\left(\lambda_{i}, I_{i}\right)=\left\{\begin{array}{cc}
k C_{i} \cdot P\left(I_{i}>M\right) & \\
+\left[\lambda_{i} \theta C_{i}+\left(1-\lambda_{i}\right) C_{i}\right] & \\
\cdot P\left(I_{i} \leq M\right), & 1 \leq i \leq n-1 \\
k\left(C_{n}+F\right) \cdot P\left(I_{n}>M\right) & \\
+\left[\lambda_{n} \theta\left(C_{n}+F\right)\right. & \\
\left.+\left(1-\lambda_{n}\right)\left(C_{n}+F\right)\right] & \\
\cdot P\left(I_{n} \leq M\right), & i=n .
\end{array}\right.
$$

Let

$$
V^{(l)}=\frac{1}{l} \sum_{j=1}^{l} \sum_{i=1}^{n} e^{-r \cdot i \Delta t} H\left(\lambda_{i}^{(j)}, I_{i}^{(j)}\right) .
$$

Assuming expression (3) exists, we can approximate the price of the CAT bond as $V=\lim _{l \rightarrow \infty} V^{(l)}$ where the number of simulation paths is $l$. So the price of the CAT bond at time 0 can be calculated by Monte Carlo method. We will give more detail of the method in Section 4. Because $P\left(I_{i}>M\right)=1-$ $P\left(I_{i} \leq M\right)$, so the key for the CAT bond pricing is to obtain the probability of default $\lambda_{i}$ and the probability distribution of loss process $I_{i}$. 
3.2. Credit Risk. This paper uses the methodology of Jarrow and Turnbull [14] to model the credit risk of the CAT bond. The credit risk can be described by the probability of default and the recovery value which are deduced by the arbitragefree valuation techniques. This methodology is simple and fits the existing term structure of interest rate well. As the absolute priority rule is often violated and lots of other factors affect the payoff of bonds, such as the percentage of managerial ownership [14], modeling the actual payoff in default is a complicated problem. Therefore, we take the recovery rate in the event of default when the CAT bond does not trigger as an exogenously given constant. The recovery rate is denoted by $\theta$ and it is assumed to be the same for all bonds in a given credit ranking. Then, we can use the riskfree interest rate to discount the cash flow of the CAT bond but not use the discount rate involving risk premium [15]. In fact, the probability of default has reflected the credit risk of the CAT bond.

Suppose the probability of default in time interval $[i-1, i]$ is denoted by $\lambda_{i}$, and let $\lambda_{i}^{*}=-(1 / i) \sum_{t=1}^{i} \ln \left(1-\lambda_{t}\right)$; then we get $\prod_{t=1}^{i}\left(1-\lambda_{t}\right)=e^{-\lambda_{i}^{*} \cdot i}$. If $\lambda_{i}$ is small, then we can obtain

$$
\lambda_{i}^{*} \approx \frac{\sum_{t=1}^{i} \lambda_{t}}{i}
$$

It means that $\lambda_{i}^{*}$ is the average intensity of default.

The interest rate of the risk bond in time interval $[i-1, i]$ is denoted by $r_{i}^{*}$ and the risk-free interest rate is $r_{i}$. For the no-arbitrage principle, parameters $r_{i}, r_{i}^{*}, \theta, \lambda_{i}^{*}$ meet the equation $e^{-r_{i}^{*}}=\left[1 \cdot\left(1-\lambda_{i}^{*}\right)+\theta \cdot \lambda_{i}^{*}\right] e^{-r_{i}}$, and then we get

$$
\lambda_{i}^{*}=\frac{1-e^{r_{i}-r_{i}^{*}}}{1-\theta} .
$$

Consequently, we can obtain the average intensity of default $\lambda_{i}^{*}$ by (6) and deduce the probability of default in each time interval $[i-1, i]$ which is $\lambda_{i}, i=1,2, \ldots, n$.

3.3. Distribution of Loss Function. The loss function $I_{i}$ is the maximum loss amount of the catastrophic event at period $i$ and $I_{i}=\max \left\{X_{1 i}, X_{2 i}, \ldots, X_{m i}\right\}$, where $m$ is the number of days at each period and $X_{1 i}, X_{2 i}, \ldots, X_{m i}$ is the sequence of loss amount at each period. They are independent random variables with a common unknown distribution function. If there exist sequences of constants $\left\{a_{k}: a_{k}>0, \forall k \in \mathbb{N}\right\}$, $\left\{b_{k}\right\}_{k \in \mathbb{N}}$ and a nondegenerate distribution function $G(z)$, such that

$$
P\left(\frac{I_{k}-b_{k}}{a_{k}} \leq z\right) \longrightarrow G(z), \quad \text { as } k \longrightarrow \infty, z \in \mathbb{R}
$$

then by Fisher-Tipptt Gnedenko Theorem, $G$ is a member of the generalized extreme value (GEV) family of distributions or von Mises Type Extreme Value distribution or the von Mises-Jenkinson type distribution [16] and its distribution function form can be denoted as

$$
G(z)=\exp \left\{-\left[1+\xi\left(\frac{z-\mu}{\sigma}\right)\right]^{-1 / \xi}\right\}
$$

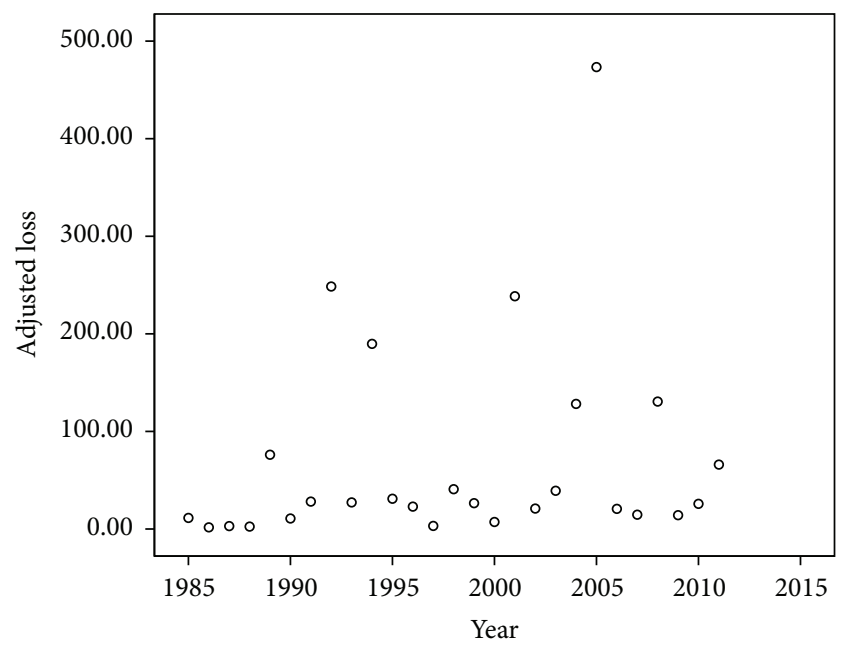

FIGURE 1: Scatter plot of the annual maximum magnitude of catastrophe losses in the USA (1985-2011).

It is defined on the set $\{z: 1+\xi(z-\mu) / \sigma>0\}$, where the scale parameter satisfies $\sigma>0$, and the trail index satisfies $-\infty<\xi<\infty$ and location parameter satisfies $-\infty<\mu<$ $\infty$. If we got the estimated values of the three parameters, the distribution function of the maximum loss amount in a catastrophic event $I_{i}$ can be gotten [17].

There are different kinds of considerable estimation techniques for three parameters $\{\sigma, \xi, \mu\}$, such as Generalized Method of Moments, the graphical techniques based on versions of probability plots, and maximum likelihood estimation (MLE) method. The MLE method is a classical estimation technique, and it is effective for the estimations of parameters $\{\sigma, \xi, \mu\}$ studied by many researchers [18-20]. We employ MLE method to estimate parameters. Suppose that the loss amount processes $I_{1}, I_{2}, \ldots, I_{n}$ are independent variables following GEV distribution; then the log-likelihood function for parameters $\mu, \sigma, \xi$ is

$$
\begin{aligned}
L(\sigma, \xi, \mu)= & n \log \sigma-\left(1+\frac{1}{\xi}\right) \sum_{i=1}^{n} \log \left[1+\xi\left(\frac{I_{i}-\mu}{\sigma}\right)\right] \\
& -\sum_{i=1}^{n}\left[1+\xi\left(\frac{I_{i}-\mu}{\sigma}\right)\right]^{-1 / \xi},
\end{aligned}
$$

where $1+\xi\left(\left(I_{i}-\mu\right) / \sigma\right)>0$, as $i=1,2, \ldots, n$.

\section{Numerical Analysis}

4.1. Data and Parameter Estimations. The analysis is based on the catastrophe data from Property Claim Services (PSC). The data covers all losses resulting from natural catastrophic events in the USA over the period 1985-2011, with 3628 original data. We get the series of annual maximum magnitude of catastrophe losses in the USA. In order to facilitate comparison, the data is adjusted for inflation given the time value of the capital, using the Consumer Price Index (CPI) provided by the US Department of Labor. Figure 1 shows the 
TABLE 1: Descriptive statistic of catastrophe losses data (billion dollars).

\begin{tabular}{lcccccccc}
\hline \multirow{2}{*}{ Sample size $(n)$} & \multirow{2}{*}{ Minimum } & \multirow{2}{*}{ Maximum } & \multirow{2}{*}{ Mean } & \multirow{2}{*}{ Standard deviation } & \multicolumn{2}{c}{ Skewness } & \multicolumn{2}{c}{ Kurtosis } \\
& & & & & Statistic & Std. error & Statistic & Std. error \\
\hline 27 & 0.168 & 4.7337 & 7.046 & 10.697 & 2.539 & 0.448 & 7.193 & 0.872 \\
\hline
\end{tabular}

adjusted annual maximum magnitude of losses. As described in Table 1, the mean of catastrophe losses is 7.046 billion, the standard deviation is 10.697 billion, the skewness is 2.54 , and the kurtosis is 7.19. It means that the data is right-skewed and tail-dispersed.

Assume that the data is independent random variables with GEV distribution function. By the extRemes program package in $\mathrm{R}$ software, we get the Maximum Likelihood estimations of parameters in distribution function (10) as follows:

$$
(\mu, \sigma, \xi)=(16.22,20.25,1.02)
$$

The covariance matrix of the three parameters estimations is

$$
\operatorname{cov}=\left[\begin{array}{ccc}
23.40 & 25.99 & -0.53 \\
25.99 & 38.36 & 0.14 \\
-0.53 & 0.14 & 0.11
\end{array}\right]
$$

Figure 2 shows the various plots for assessing the accuracy of the GEV model, fitted to the annual maximum magnitude of catastrophe losses of US data. Each set of plotted points is near-line in the probability plot and the quantile plot, so the fitted model is valid. The respective estimated curve in the return level plot is close to a straight line and the corresponding density plot seems consistent with the histogram of the data. Therefore, the estimated GEV distribution fits the real data well and the GEV model, deduced by the MLE method, is acceptable and valid. Then, we use the estimations of the model parameters to calculate the probability of the catastrophe loss by (9).

Now, we consider the credit risk. The credit ratings of most CAT bonds are $\mathrm{BB}$, while a CAT bond rated AA was issued in 2006 for the first time. So we assume that the credit rating of the CAT bond is BB. Furthermore, we take the treasury rates in the US market as the risk-free interest rate and take the corporation bonds rates as the risk rates. Suppose the recovery rate $\theta=40 \%$ when the CAT bond defaults. Then, according to the US market data in July, 2013, the treasury rates of 6 months, 2 years, 3 years, and 5 years are $0.06 \%, 0.39 \%, 0.74 \%$, and $1.61 \%$,respectively, and the corresponding rates of corporation bonds rated $\mathrm{BB}$ are $3.05 \%$, $5.24 \%, 6.83 \%$, and $7.35 \%$, respectively. We get the treasury rates and corporation bonds rates from the risk-free interest rates and the risk interest rates, respectively, over the time period of 1-5 years by the linear interpolation method as Table 2 shows. Moreover, we get the default rates of risk bonds in each period by expressions (6) and (7), just as Table 3 shows.

4.2. Pricing Analysis. Consider a CAT bond with the duration $n=5$ years, the face value $F=100$ dollars, and the coupon rate $9 \%$. The amount of trigger loss is assumed to be the mean
TABLE 2: Risk-free interest rates and risk interest rates.

\begin{tabular}{lccccc}
\hline Time & 1 & 2 & 3 & 4 & 5 \\
Risk-free & $0.17 \%$ & $0.39 \%$ & $0.74 \%$ & $1.18 \%$ & $1.61 \%$ \\
Risk & $3.78 \%$ & $5.24 \%$ & $6.83 \%$ & $7.09 \%$ & $7.35 \%$ \\
\hline \multicolumn{5}{c}{ TABLE 3: Default rates of risk bonds. } \\
\hline Time period & $0-1\left(\lambda_{1}\right)$ & $1-2\left(\lambda_{2}\right)$ & $2-3\left(\lambda_{3}\right)$ & $3-4\left(\lambda_{4}\right)$ & $4-5\left(\lambda_{5}\right)$ \\
Default rate & $5.92 \%$ & $9.86 \%$ & $13.77 \%$ & $8.72 \%$ & $8.23 \%$ \\
\hline
\end{tabular}

of the loss amount; that is to say, $M=7.046$ billion dollars. The obtained ratio of the interest and the principal when the CAT bond triggers is $k=0.8$. Then, we get the probability of trigger $P(I>M)=0.2404$ by expression (9) substituting the above-mentioned parameters. Then by (9), we deduce

$$
z=\mu+\left[\sigma\left(1-(-\log G(z))^{-\xi}\right)\right] .
$$

As the function $G(z)$ is the distribution probability, it meets $0 \leq G(z) \leq 1$. So by generating random numbers on the interval $[0,1]$, we simulate the variable $z$ employing the Monte Carlo method with the number of simulation paths $l=$ 10000. For expression (4), we get the pricing result of the CAT bond which is $V=118.86$ dollars by the Matlab software. In the same way, the price of fixed income instrument without credit risk is calculated as 139.27 dollars with the same interest rates. The former is much less than the latter that attributes to the risk of catastrophe and the credit risk. For a higher risk, the CAT bond gives a higher yield.

\section{Conclusions}

As catastrophes are small probability and high loss events and present high positive correlation among individuals, the traditional insurance company and reinsurance company may not spread risk completely. However, the securitization of catastrophe risk brings an effective solution to transfer and spread the catastrophe risk. In order to develop the CAT bond market, it is necessary to make effective pricing to CAT bond which is the most mature instrument in catastrophe securitization at the present. To make the pricing result accurate, the credit risk in the CAT bond should not be ignored. This paper builds the model of the CAT bond involving the credit risk. This model has the characteristics of an analytic method and numerical method and has a good practical feasibility. We employ the Jarrow and Turnbull method to model the credit risk and get access to the general pricing formula using the Extreme Value Theory. Furthermore, we present an empirical pricing study of the Property Claim Services data where the parameters in the loss function distribution are estimated by the MLE method and the default probabilities are deduced 

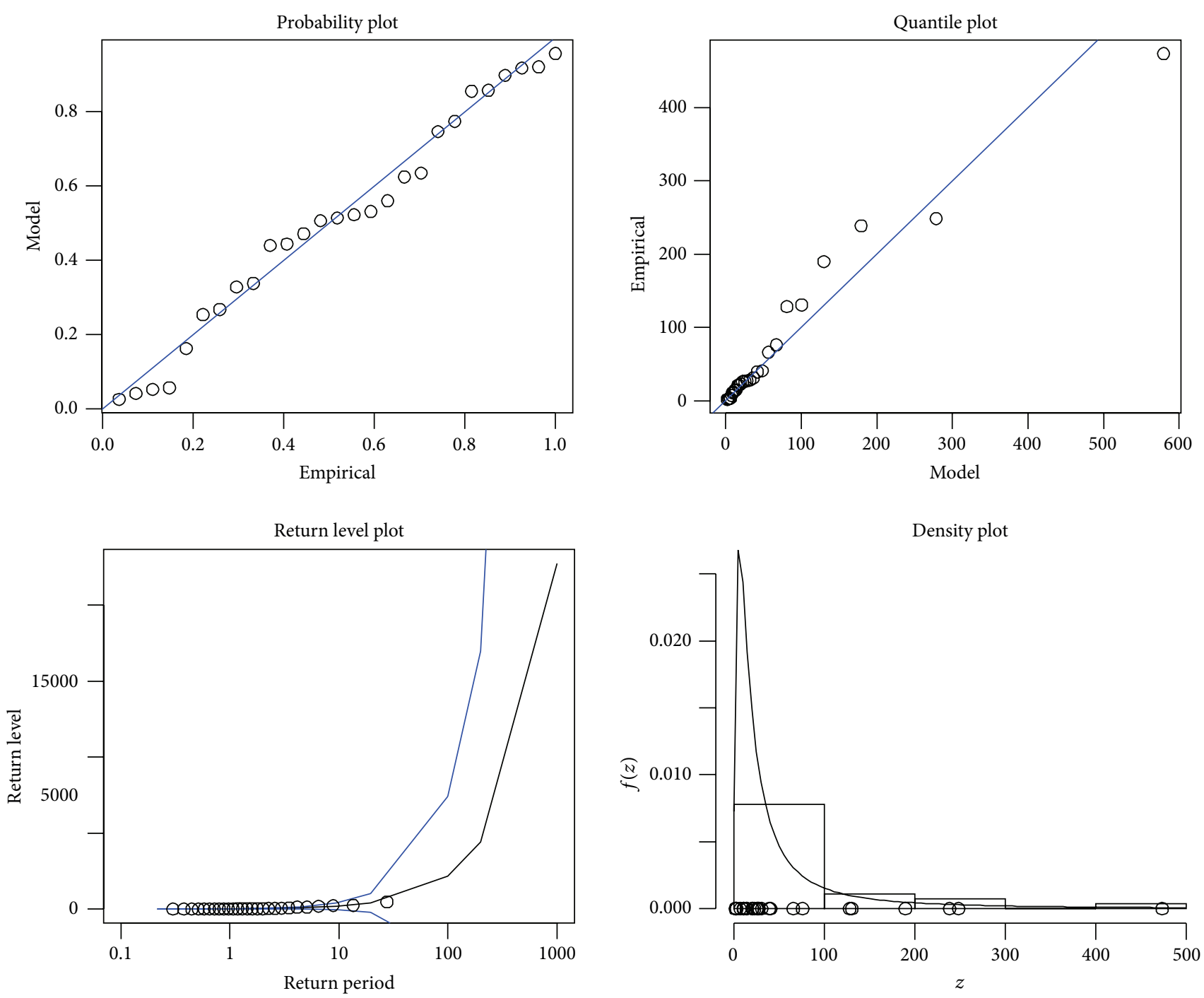

FIGURE 2: Diagnostic plots for GEV fit to the annual maximum magnitude of catastrophe losses in the USA.

by the US financial market data. Consequently, we get the catastrophe bonds value by the Monte Carlo method which is lower than the price of fixed income instruments.

Further research is directed to extend the model in more complex situations, for example, given suitable stochastic process to describe the trigger amount of loss, and it will perfect the model which we have discussed.

\section{Conflict of Interests}

The authors declare that there is no conflict of interests regarding the publication of this paper.

\section{Acknowledgments}

The authors would like to express their gratitude to the support given by the Natural Science Foundation of China (no. 71201013, no. 71171024, and no. 71371195), the Humanities and Social Sciences Project of the Ministry of Education of China (no. 12YJC630118), and the Hunan Social Science Planning Project of China (no. 11YBA009).

\section{References}

[1] http://finance.sina.com.cn/world/mzjj/20131018/171517040051. shtml.

[2] R. Kreps, "Investment-equivalent reinsurance pricing," in Proceedings of the Casualty Actuarial Society (PCAS '98), vol. 85, May 1998.

[3] M. N. Lane, Price, Risk, and Ratings for Insurance-Linked Notes: Evaluating Their Position in Your Portfolio, Derivatives Quarterly, 1998.

[4] M. N. Lane and O. Y. Movchan, "Risk cubes or price risk and ratings (Part II)," Journal of Risk Finance, vol. 1, no. 1, pp. 71-86, 1999.

[5] S. Christofides, Pricing of Catastrophe Linked Securities, ASTIN Colloquium International Actuarial Association, Brussels, Belgium, 2004. 
[6] S. Wang, Pricing of Catastrophe Bonds, Alternative Risk Strategies, Risk Press, 2002.

[7] A. A. Zimbidis, N. E. Frangos, and A. A. Pantelous, "Modeling earthquake risk via extreme value theory and pricing the respective catastrophe bonds," Astin Bulletin, vol. 37, no. 1, pp. 163-183, 2007.

[8] Z.-G. Ma and C.-Q. Ma, "Pricing catastrophe risk bonds: a mixed approximation method," Insurance: Mathematics \& Economics, vol. 52, no. 2, pp. 243-254, 2013.

[9] Y. Li, B. Fan, and J. Liu, "Design and pricing of multi-event CAT bonds: a case of typhoon bonds in China," China Soft Science Magazine, no. 3, pp. 41-48, 2012.

[10] H. Xiao and S. Meng, "EVT and its application to pricing of catastrophe reinsurance," Journal of Applied Statistics and Management, vol. 32, no. 2, pp. 240-246, 2013.

[11] P. Nowak and M. Romaniuk, "Pricing and simulations of catastrophe bonds," Insurance: Mathematics \& Economics, vol. 52, no. 1, pp. 18-28, 2013.

[12] F. Wen, Z. He, and X. Chen, "Investors' risk preference characteristics and conditional skewness," Mathematical Problems in Engineering, vol. 2014, Article ID 814965, 14 pages, 2014.

[13] C. Huang, X. Gong, X. Chen, and F. Wen, "Measuring and forecasting volatility in Chinese stock market using HAR-CJM model," Abstract and Applied Analysis, vol. 2013, Article ID 143194, 13 pages, 2013.

[14] R. A. Jarrow and S. M. Turnbull, "Pricing derivatives on financial securities subject to credit risk," Journal of Finance, vol. 50, no. 1, pp. 53-85, 1995.

[15] J. Huang, J. Liu, and Y. Rao, "Binary tree pricing to convertible bonds with credit risk under stochastic interest rates," Abstract and Applied Analysis, vol. 2013, Article ID 270467, 8 pages, 2013.

[16] S. Kotz and S. Nadarajah, Extreme Value Distributions, Imperial College Press, London, UK, 2000.

[17] L. Yu, S. Wang, F. Wen, and K. K. Lai, "Genetic algorithm-based multi-criteria project portfolio selection," Annals of Operations Research, vol. 197, no. 1, pp. 71-86, 2012.

[18] J. Hosking, "Algorithm AS 215: maximum-likelihood estimation of the parameters of the generalized extreme-value distribution," Journal of the Royal Statistical Society, vol. 34, pp. 301-310, 1985.

[19] J. Liu, L. Yan, and C. Ma, "Pricing options and convertible bonds based on an actuarial approach," Mathematical Problems in Engineering, vol. 2013, Article ID 676148, 9 pages, 2013.

[20] C. Huang, C. Peng, X. Chen, and F. Wen, "Dynamics analysis of a class of delayed economic model," Abstract and Applied Analysis, vol. 2013, Article ID 962738, 12 pages, 2013. 


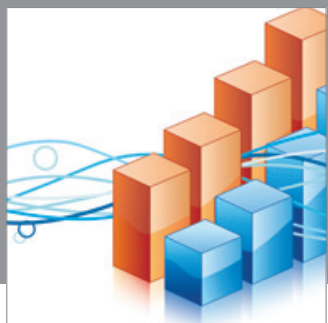

Advances in

Operations Research

mansans

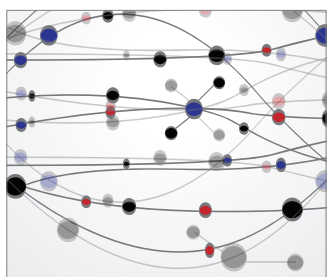

The Scientific World Journal
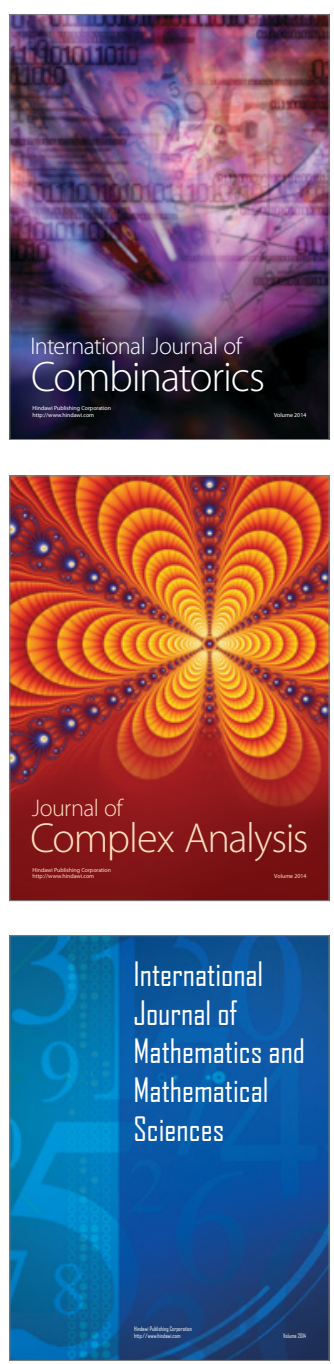
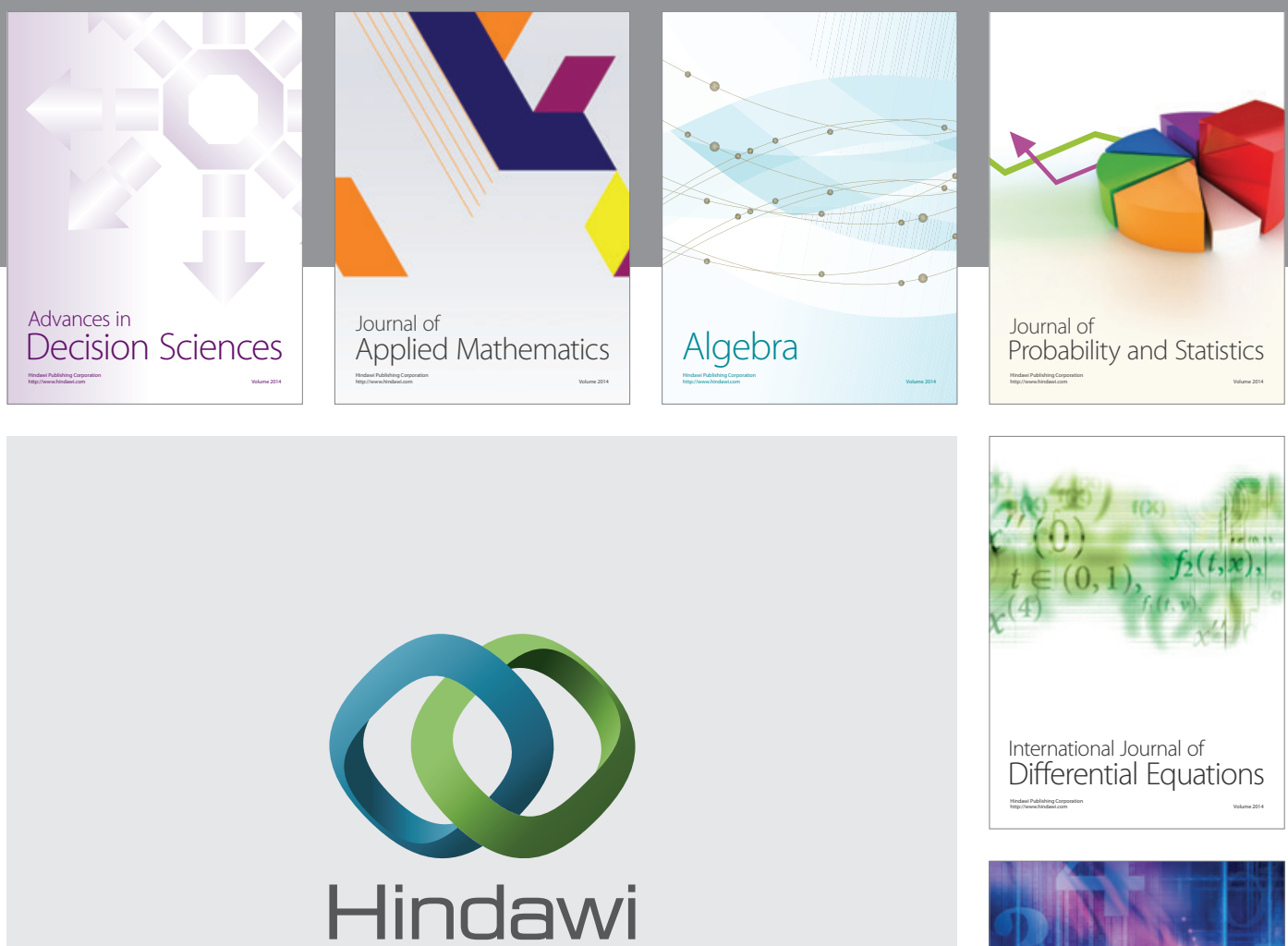

Submit your manuscripts at http://www.hindawi.com
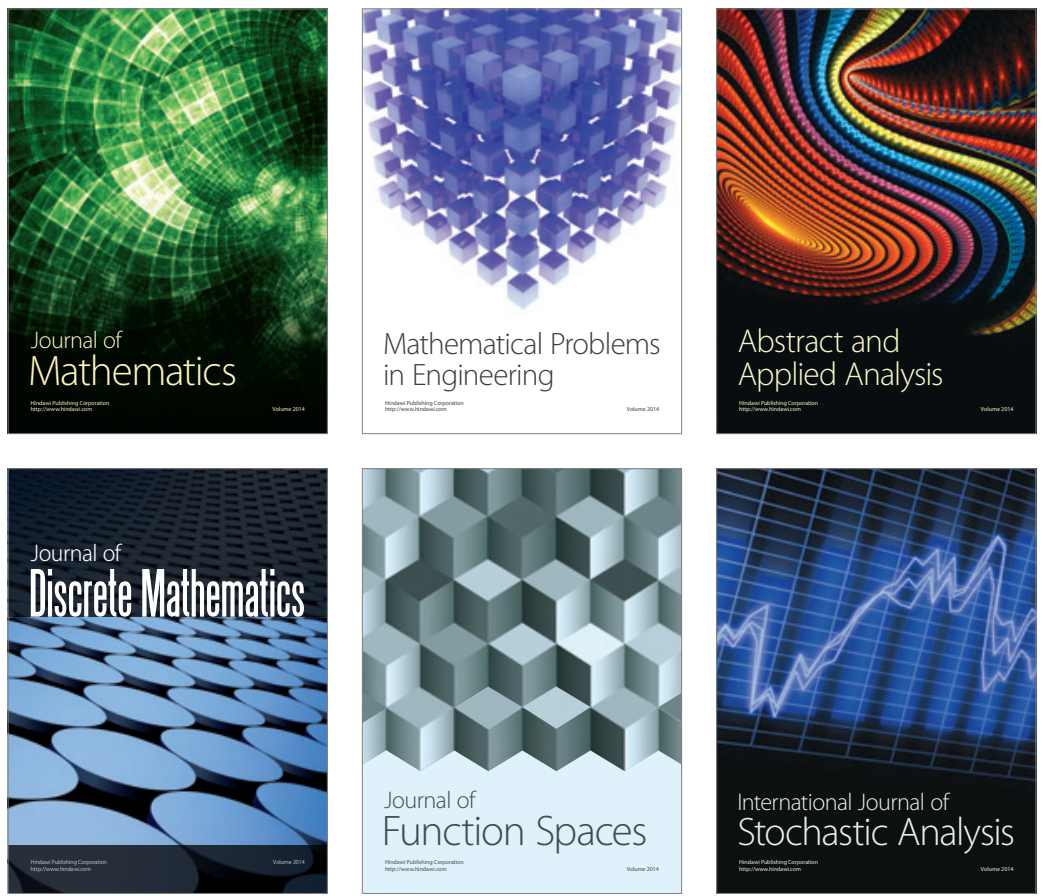

Journal of

Function Spaces

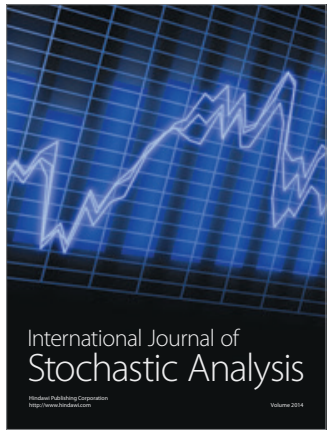

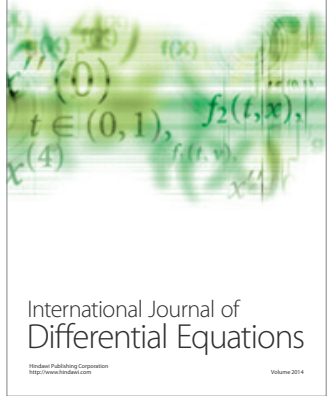
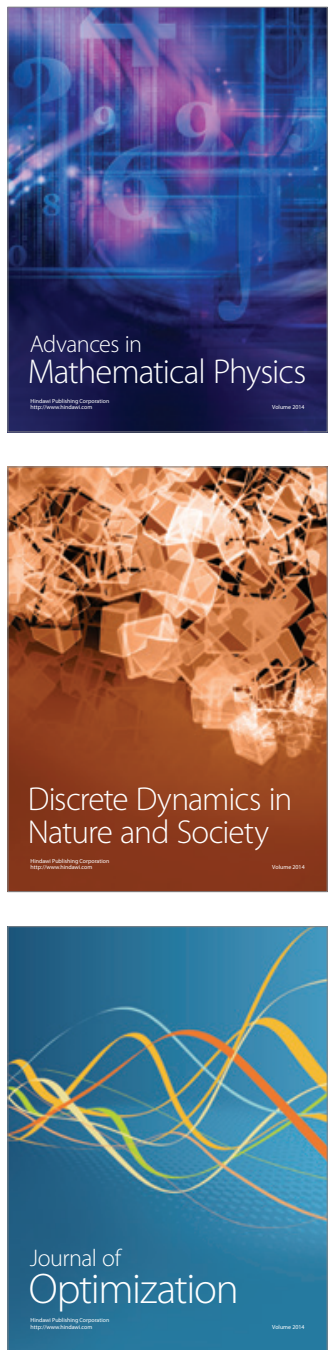